\title{
Considerações paleobiogeográficas baseadas em braquiópodes devonianos (Delthyridoidea, Strophodontoidea e Chonetoidea) das bacias do Amazonas e Parnaíba \\ Paleobiogeographic observations based on Devonian brachiopods (Delthyridoidea, Strophodontoidea and Chonetoidea) of the Amazon and Parnaíba basins
}

\author{
Vera Maria Medina da Fonseca \\ Museu Nacional/Universidade Federal do Rio de Janeiro. Rio de Janeiro, Rio de Janeiro, Brasil
}

\begin{abstract}
Resumo: Revisões sistemáticas de braquiópodes devonianos das bacias do Amazonas e Parnaíba reforçaram a constatação prévia da coexistência de formas dos domínios das Américas Orientais, Malvinocáfrico e do Velho Mundo, além de formas endêmicas nelas. Uma causa provável dessa composição mista é a posição paleogeográfica das bacias brasileiras e, sobretudo, a idade eifeliana-givetiana das macrofaunas, coincidente com as idades estimadas para o desaparecimento dos domínios Malvinocáfrico e das Américas Orientais. Estrofodontoides eram abundantes no Eodevoniano-Mesodevoniano dos domínios das Américas Orientais e do Velho Mundo, enquanto no Brasil as poucas formas identificadas restringem-se à Formação Maecuru. A ausência destas formas nas outras formações aqui tratadas, aliada à presença de gêneros malvinocáfricos nelas, amplia a provável influência das faunas 'malvinocáfricas' a partir do Eifeliano nas bacias do Norte e Nordeste do Brasil. Nos Chonetoidea, foi verificado um padrão similar entre as formas e a dinâmica da mistura de faunas das formações Maecuru/Pimenteira e Ererê/Membro Passagem com aquelas da região sul-saariana, no noroeste da África. Interessante também é a relação dessas paleofaunas brasileiras com as da Armórica (Europa norte-gondwânica) no Devoniano. Alguns táxons de braquiópodes e outros grupos, como os crinoides, sugerem uma troca faunística entre essas regiões durante o Devoniano.
\end{abstract}

Palavras-chave: Braquiópode. Devoniano. Paleobiogeografia. Bacias do Amazonas e Parnaíba. Chonetoidea. Strophodontoidea.

Abstract: Systematic revisions of Devonian brachiopods of the Amazon and Parnaiba basins reinforced the previous observations of the coexistence of the Eastern Americas, Old World and Malvinokaffric Realms forms, besides endemic forms in both basins. A possible cause of this mixed composition is the paleogeographic position of the Brazilian basins, and especially the Eifelian-Givetian age of macrofaunas coincident with those estimated for the disappearance of Malvinokaffric and Eastern Americas Realms. Strophodontoids were abundant in Early-Middle Devonian of the Eastern Americas and Old World Realms, while in Brazil the few forms identified are restricted to Maecuru Formation. The absence of these forms in the others formations here discussed, together with the presence of the Malvinokaffric genus in these formations, expands the probable influence of the Malvinokaffric Eifelian faunas in the basins of the North and Northeast of Brazil. Among Chonetoidea, a similar pattern was observed between the forms and dynamics of mixed faunas of the brazilian formations cited above with those of south-Saharan region in northwest Africa. Interesting is also the relationship of these Brazilian paleofaunas with those of Armorica (North Gondwanan Europe) in the Devonian. Some taxa of brachiopods and crinoids, suggest a faunal exchange between these regions during this time.

Keywords: Brachiopod. Devonian. Paleobiogeography. Amazonas and Parnaíba basins. Chonetoidea. Strophodontoidea.

FONSECA,V. M. M., 2015. Considerações paleobiogeográicas baseadas em braquiópodes devonianos (Delthyridoidea, Strophodontoidea e Chonetoidea) das bacias do Amazonas e Parnaíba. Boletim do Museu Paraense Emílio Goeldi. Ciências Naturais 10(1): 91-101.

Autor para correspondência: Vera Maria Medina da Fonseca. Museu Nacional/Universidade Federal do Rio de Janeiro. Quinta da Boa Vista, s/n. Rio de Janeiro, RJ, Brasil. CEP 20940-040 (vmmedinafonseca@gmail.com).

Recebido em 04/03/2015

Aprovado em 29/04/2015

Responsabilidade editorial: Hilton Tulio Costi

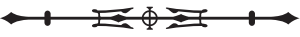




\section{INTRODUÇÃO}

Consta na literatura que as bacias do Amazonas e Parnaíba possuíram, durante o Mesodevoniano, uma fauna mista de macroinvertebrados marinhos com componentes dos domínios das Américas Orientais e Malvinocáfrico, além de formas endêmicas e alguns poucos gêneros do domínio do Velho Mundo (Melo, 1988; Boucot, 1988). Revisões sistemáticas mais recentes de alguns grupos de braquiópodes reforçaram a constatação da coexistência de formas originárias dos três grandes domínios paleobiogeográficos nas duas bacias, além de evidenciarem a existência de diacronismo entre as ocorrências de gêneros de braquiópodes presentes nas bacias brasileiras e as registradas em outras regiões paleogeográficas devonianas. Este trabalho resulta das observações feitas durante uma revisão sistemática dos braquiópodes das superfamílias Strophomenoidea, Chonetoidea e Delthyridoidea do Devoniano Médio das bacias do Amazonas e Parnaíba (Fonseca, 2001, 2004). Nele, serão apresentadas considerações acerca de relações paleobiogeográficas das citadas bacias, objetivando contribuir para o entendimento da distribuição paleobiogeográfica das paleofaunas de organismos bentônicos devonianos, assim como para pesquisas futuras.

\section{ÁREAS DE ESTUDO}

\section{BACIA DO AMAZONAS}

Os sedimentos fossiliferos devonianos da Bacia do Amazonas, portadores dos braquiópodes aqui tratados, são procedentes, em sua maioria, de afloramentos situados na faixa expositiva de estratos paleozoicos, que paralelizam, ao norte, o curso do rio Amazonas no estado do Pará. Boas exposições também são encontradas em áreas fortemente erodidas, em consequência de soerguimento tectônico em tempos pós-paleozoicos, como a estrutura dômica de Monte Alegre caracterizada por cobertura vegetal rarefeita, e onde se situa o povoado de Ererê, também no estado do Pará (Fonseca \& Ponciano, 2011).

Esses sedimentos constituem as formações Maecuru (Cunha et al., 2007) e Ererê. A primeira é composta sobretudo por arenitos neríticos a flúvio-deltaicos, com raras intercalações de pelitos, de idade neoemsiana a eoeifeliana bem determinada por miósporos (Melo \& Loboziak, 2003) e quitinozoários (Grahn \& Melo, 2004; Fonseca \& Ponciano, 2011). Os clásticos flúvio-deltaicos a neríticos mais grossos da Formação Maecuru são sucedidos, em concordância, pelos clásticos neríticos, dominantemente siltitos, argilitos e arenitos finos, da Formação Ererê resultantes do aprofundamento da lâmina de água (Cunha et al., 2007). Análises palinológicas dos sedimentitos neríticos da Formação Ererê determinaram sua idade como neoeifeliana a eogivetiana (Melo \& Loboziak, 2003; Grahn \& Melo, 2004).

As camadas portadoras de macrofósseis de invertebrados da Formação Maecuru restringem-se à sua porção superior e apresentam a maior diversidade faunística do Devoniano brasileiro. Juntamente com os braquiópodes, esses arenitos exibem restos de moluscos, trilobitas, briozoários, corais, crinoides, conularíidas e tentaculítidas (Melo, 1988). A paleofauna da Formação Ererê é menos diversificada do que a da Formação Maecuru, sendo, em sua maioria, procedente de arenitos de granulometria fina, provavelmente situados na seção inferior da formação. Além de braquiópodes, foram identificados trilobitas, moluscos, ostracodes, crinoides, escolecodontes e tentaculĺtidas (Melo, 1988).

As localidades clássicas do Devoniano da Bacia do Amazonas, onde foram coletados invertebrados fósseis pelas expedições Morgan, Comissão Geológica do Império e pelo geólogo Friedrich Katzer, no século XIX, são citadas na literatura apenas como 'rio Maecuru', 'rio Curuá' e 'Ererê', no estado do Pará. Em 1986, a 'expedição Orville A. Derby', promovida pelo Centro de Pesquisas da Petróleo Brasileiro S.A. (PETROBRAS) e liderada pelo geólogo José Henrique Gonçalves de Melo, revisitou as localidades fossilíferas clássicas do Devoniano das bacias sedimentares brasileiras. Nesta ocasião, a localização geográfica dos afloramentos do rio Maecuru foi estabelecida com maior precisão. A maior parte dos braquiópodes da Formação Maecuru aqui tratados foi coletada na margem direita do rio Maecuru em três pontos à montante da cachoeira Teuapixuna ou Alagação 
(400 m, 600 m e 900 m), e na própria cachoeira, situada cerca de 1,2 km à montante da foz do igarapé Ipixuna. Os braquiópodes da Formação Ererê foram coletados no igarapé Ipixuna (cerca de $1 \mathrm{~km}$ à montante de sua foz no rio Maecuru), na margem direita do rio Maecuru (cerca de $2 \mathrm{~km}$ à jusante da foz do igarapé Ipixuna), na planície de Ererê e no rio Erepecuru, tributário do rio Trombetas. As localidades de coleta no rio Maecuru situam-se entre as longitudes $54^{\circ}$ 22' e 54⒉' W e latitudes 1034' e 1035' S, entre o igarapé Ipixuna e a corredeira Vibração (Fonseca, 2004).

\section{BACIA DO PARNAÍBA}

Sedimentos paleozoicos afloram nos flancos leste e oeste da bacia do Parnaíba. Os estratos devonianos nos dois flancos originaram-se em paleoambientes parálicos a marinhos rasos, no transcorrer de um ciclo transgressivoregressivo que se iniciou no Eifeliano (Fonseca \& Ponciano, 2011). Os braquiópodes aqui descritos procedem da faixa de afloramentos devonianos de direção nordeste-sudoeste que delineia a borda leste da bacia, no estado do Piauí. Esses fósseis ocorrem em camadas do Devoniano Médio situadas na Formação Pimenteira e no Membro Passagem, da Formação Cabeças.

Na borda leste da bacia, a Formação Pimenteira caracteriza-se predominantemente pela intercalação de arenitos finos e micáceos, portadores de estratificação cruzada hummocky (HCS), com folhelhos e siltitos bioturbados (Vaz et al., 2007), datada através da análise de quitinozoários como neoeifeliana a eogivetiana (Grahn et al., 2008).

Uma fauna variada de invertebrados marinhos ocorre nessa formação, juntamente com restos de peixes e plantas. A parte inferior da Formação Pimenteira encontra-se bem exposta na região de Itainópolis, estado do Piauí. Ali, é representada por arenitos portadores de associações dominadas pelo braquiópode Tropidoleptus carinatus, mas que também incluem gastrópodes (Plectonotus), trilobitas homalonótidas e moluscos biválvios (Fonseca \& Melo, 1987). Em outras localidades, faunas distintas em um intervalo estratigráfico correlacionável foram registradas por Kegel
(1953). Tais faunas incluem braquiópodes 'inarticulados' e 'articulados', trilobitas homalonótidas e calmoniídas, ostracodes, biválvios, gastrópodes belerofontídeos, hiolitídeos, Tentaculites e restos de peixes elasmobrânquios. As faunas de seções intermediárias da Formação Pimenteira aflorantes no Piauí são aparentemente dominadas por espécimes de um Chonetoidea (Montsenetes of. M. boliviensis Rachebouef, 1992), incluindo, além disso, biválvios, gastrópodes e conularídas. Os fósseis da parte superior da Formação Pimenteira aflorante no leste da bacia ocorrem em arenitos e concreções ferruginosas, e consistem de braquiópodes terebratulídeos, trilobitas, gastrópodes, biválvios e conularíidas (Melo, 1988).

Os macrofósseis do Membro Passagem restringem-se a afloramentos na borda leste da bacia. Os horizontes fossilíferos ocorrem em arenitos de coloração amarelada a arroxeada, muito micáceos e de granulometria fina, com intercalações de siltitos e arenitos conglomeráticos. Juntamente com os braquiópodes, ocorrem biválvios, gastrópodes, trilobitas, tentaculídeos e crinoides, além de fragmentos vegetais (Ponciano et al., 2013). Nas amostras do Membro Passagem, não foram recuperados palinomorfos. Entretanto, a idade eogivetiana do topo da Formação Pimenteira na borda leste, determinada com base em palinomorfos em seções próximas às do Membro Passagem (Grahn et al., 2008), corrobora a proposta prévia de idade givetiana, sugerida por Melo (1985) para o referido Membro.

As localidades de coleta dos braquiópodes aqui tratados encontram-se em afloramentos facilmente acessíveis nas localidades de Picos, Oitis e seus arredores.

\section{MATERIAL}

As unidades litoestratigráficas do Devoniano Médio das bacias do Amazonas e Parnaíba, em particular as formações Maecuru, Ererê, Pimenteira e o Membro Passagem apresentam uma grande diversidade de restos de macroinvertebrados marinhos, dos quais os braquiópodes são os mais abundantes. Destacam-se aqueles pertencentes às superfamílias Strophomenoidea, 
Chonetoidea e Delthyridoidea, tanto por sua importância quantitativa nas tafocenoses das unidades mencionadas quanto pelo melhor grau de preservação dos espécimes (Fonseca \& Ponciano, 2011).

Centenas de amostras das formações Maecuru, Ererê e Pimenteira foram examinadas. Este material está depositado no Rio de Janeiro, na coleção de paleoinvertebrados do Departamento de Geologia e Paleontologia do Museu Nacional/Universidade Federal do Rio de Janeiro (MN-I) e na coleção de invertebrados fósseis do Museu de Ciências da Terra do Departamento Nacional de Produção Mineral (DGM-I e MCT-I). Foi também examinado material da Formação Pimenteira depositado no Departamento de Geologia do Instituto de Geociências da Universidade Federal do Rio de Janeiro (UFRJ) e no Departamento de Ciências Naturais da Universidade Federal do Estado do Rio de Janeiro (UNIRIO).

\section{TÁXONS IDENTIFICADOS}

Os fósseis de braquiópodes devonianos das duas bacias, conservados em arenitos e siltitos, diferentemente daqueles presentes em algumas plataformas carbonáticas, em geral não se apresentam bem conservados. Este fato torna difícil suas atribuições aos táxons estabelecidos na literatura. Por este motivo, a lista das formas estabelecidas apresenta táxons em nomenclatura aberta. Foram identificados os seguintes gêneros e espécies pertencentes às superfamílias aqui tratadas: na Formação Maecuru - Protoleptostrophia sp. (Figura 1A), Megastrophia (Megastrophia) sp. (Figura 1B), "Strophomena" hoeferi Katzer, 1903 (provavelmente um novo gênero) (Figuras 1C e 1D), Montsenetes carolinae Fonseca, 2004 (Figuras 1E e 1F), Patriaspirifer ff. P. duodenarius (Hall, 1843) (Figuras 3A e 3B) e Mucrospirifer katzeri (Clarke, 1913) (Figuras 3C e 3D); na Formação Ererê Pleurochonetes comstocki (Rathbun, 1874), "Chonetes" freitasi Rathbun, 1879 (Figuras 2E e 2F), "Chonetes" herbertsmithi Rathbun, 1874, "Chonetes" onettianus Rathbun, 1874 (os gêneros das três últimas espécies estão indicados entre aspas porque não pertencem ao gênero Chonetes, porém a precariedade de suas preservações inviabilizou designações taxonômicas confiáveis) e Mucrospirifer pedroanus (Rathbun, 1874) (Figuras 4A e 4B); na Formação Pimenteira, abaixo do Membro Passagem - Montsenetes cf. M. boliviensis Rachebouef, 1992 (Figuras 2A e 2B); no Membro Passagem - Pleurochonetes comstocki (Rathbun, 1874) (Figuras 2C e 2D) e duvidosamente Mucrospirifer pedroanus (Rathbun, 1874) (Figura 4C).

\section{CONSIDERAÇÕES PALEOBIOGEOGRÁFICAS}

Desde os trabalhos pioneiros de Rathbun (1874, 1879), a maioria das formas de braquiópodes da Bacia do Amazonas vem sendo comparada com taxa do domínio das Américas Orientais. Segundo Carvalho (1975), na primeira revisão desses fósseis desde os estudos pioneiros, a paleofauna de braquiópodes da Bacia do Amazonas corresponderia a uma assembleia de fósseis constituída, em sua maioria, por gêneros característicos da Província Apalachiana, domínio das Américas Orientais (Amphigenia, Discomyorthis, Megastrophia, Plicoplasia e Protoleptostrophia). Entre as formas comuns aos domínios das Américas Orientais e do Velho Mundo, são citados Acrospirifer, Platyorthis, Podolella e Tropidoleptus, e entre as Américas Orientais e o domínio Malvinocáfrico, Plicoplasia, Derbyina e Tropidoleptus. A distribuição paleogeográfica desses gêneros revelou-se mais ampla posteriormente. Os Chonetoidea não foram tratados neste trabalho.

Os braquiópodes da Bacia do Parnaíba têm sido objeto de comparações menos precisas. Entretanto, em alguns mapas paleogeográficos, essa região é incluída no domínio Malvinocáfrico (Boucot, 1988). Embora ainda não se tenha um inventário completo das formas de braquiópodes dessa bacia, o afluxo de formas originadas do domínio Malvinocáfrico pode ser constatado entre os Chonetoidea. As espécies Montsenetes cf. M. bolivianus e Pleurochonetes comstocki aqui identificadas são muito semelhantes a formas bolivianas, embora ocorram também em outras regiões. A preservação da única forma de Delthyridoidea examinada não permitiu uma classificação segura. 


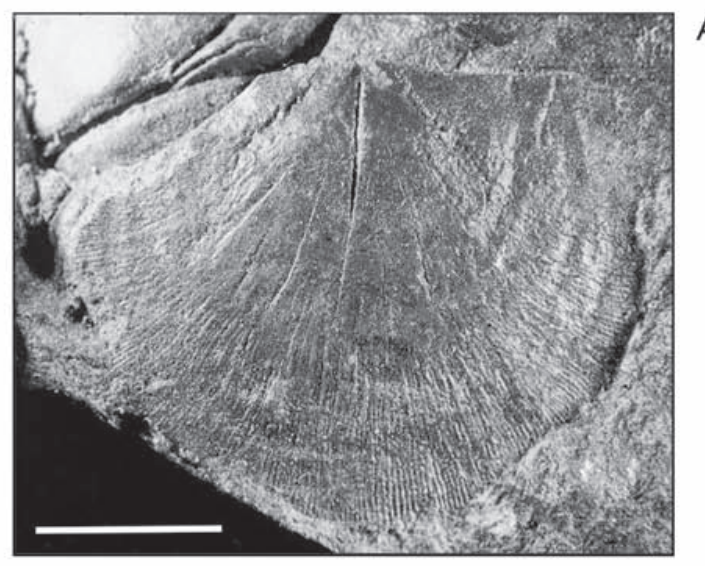

A

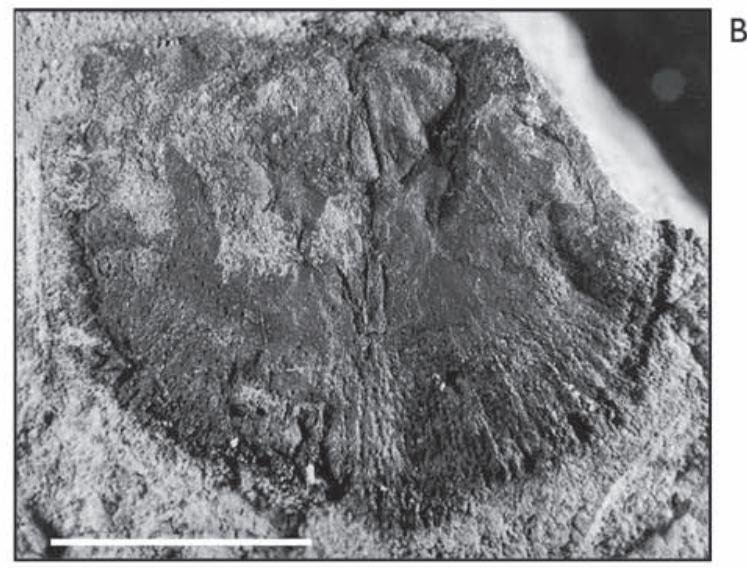

B

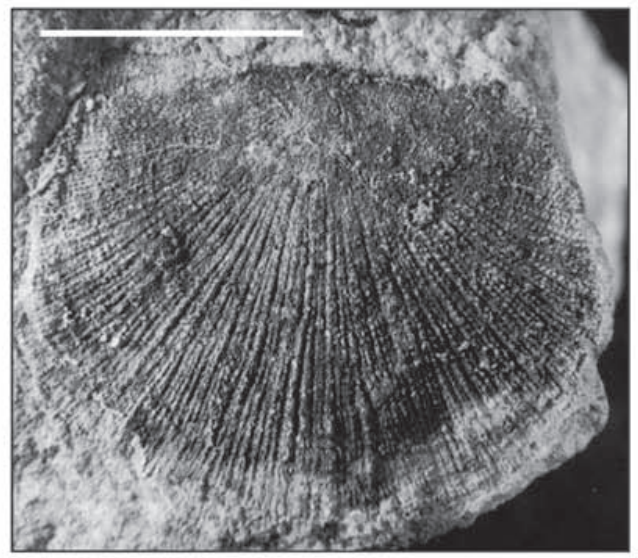

C
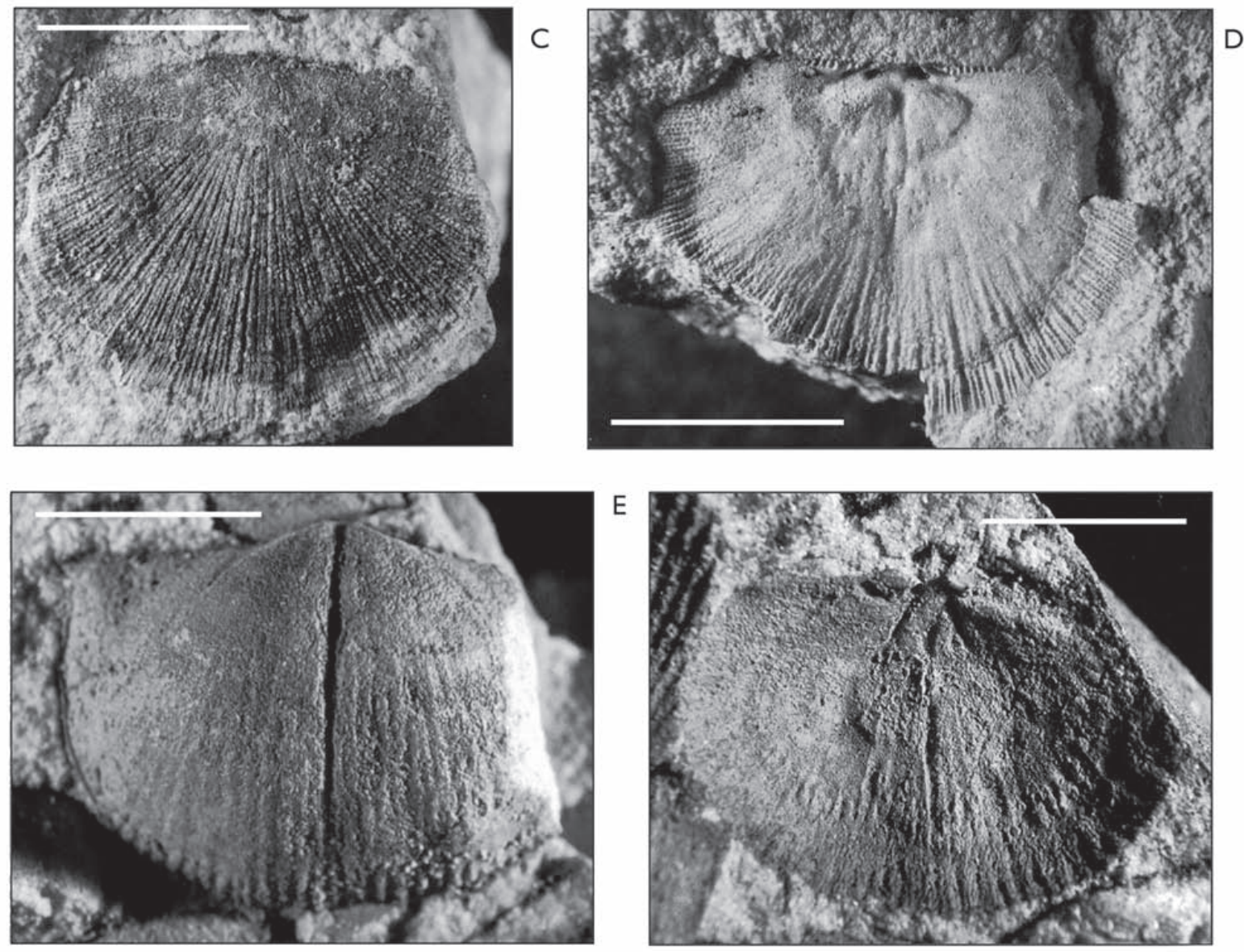

Figura 1. A) Protoleptostrophia sp. (MN 5173-I), rio Maecuru; B) Megastrophia (Megastrophia) sp. (MN 7400-la), margem direita do rio Maecuru, aproximadamente 600 m à montante da cachoeira de Teuapixuna (ou Alagação); C e D) "Strophomena" hoeferi Katzer (MN 7402-Ic e MN 7402-la), margem direita do rio Maecuru, aproximadamente 900 m à montante da cachoeira de Teuapixuna (ou Alagação); E e F) Montsenetes carolinae Fonseca (MN 7371-Ic e MN 7370-Ib, mesma localidade das Figuras 3 e 4. Figuras A a F: Formação Maecuru, Pará. Escala = 10 mm. 

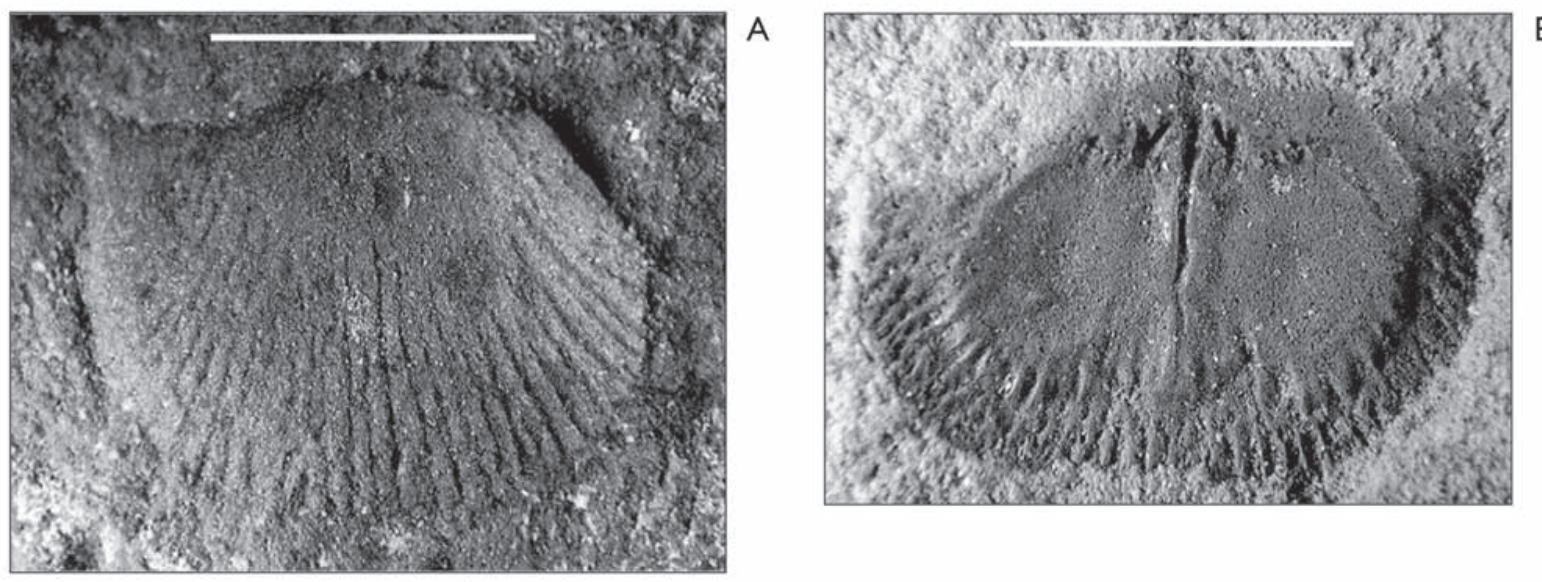

B
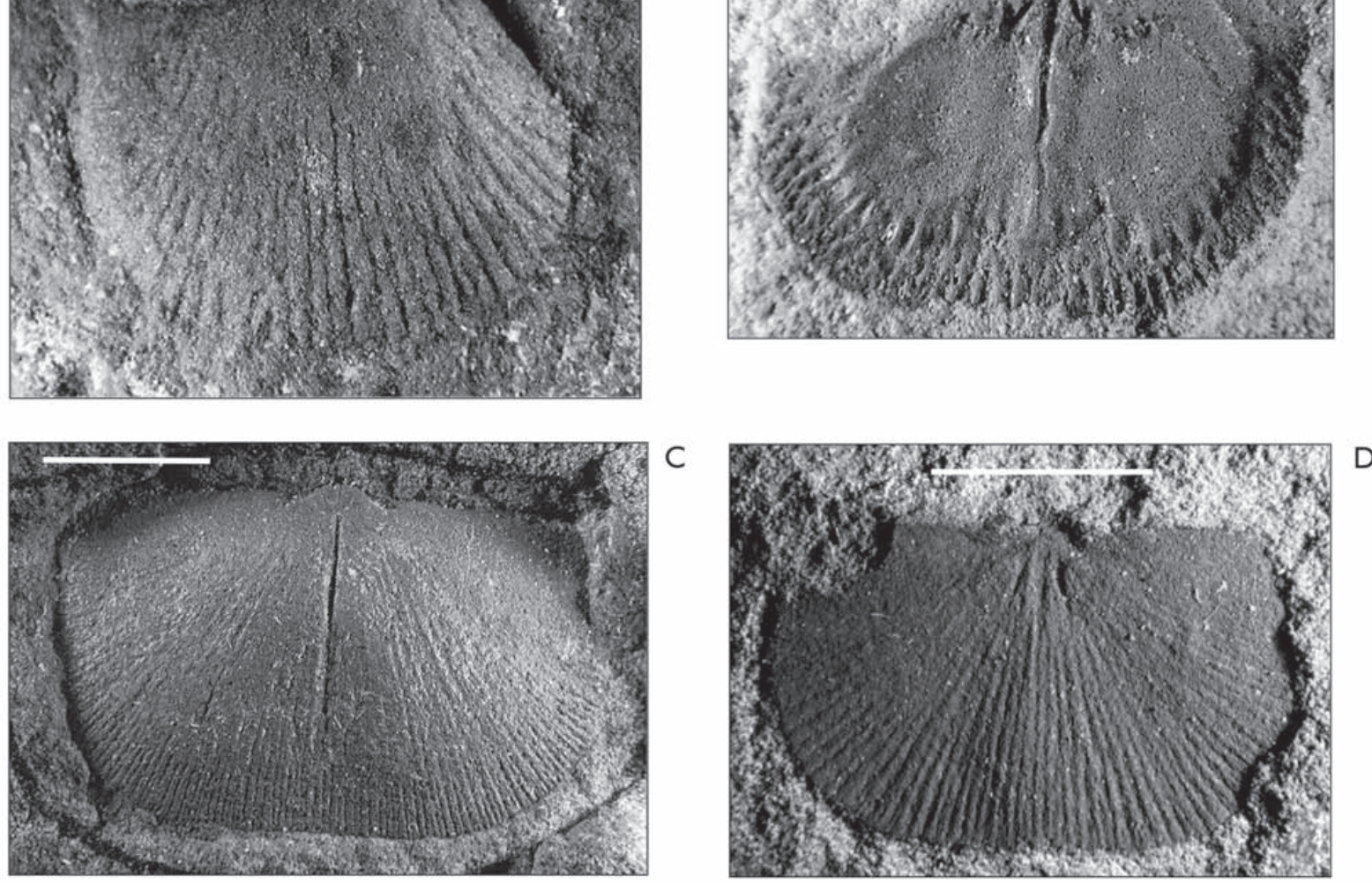

D

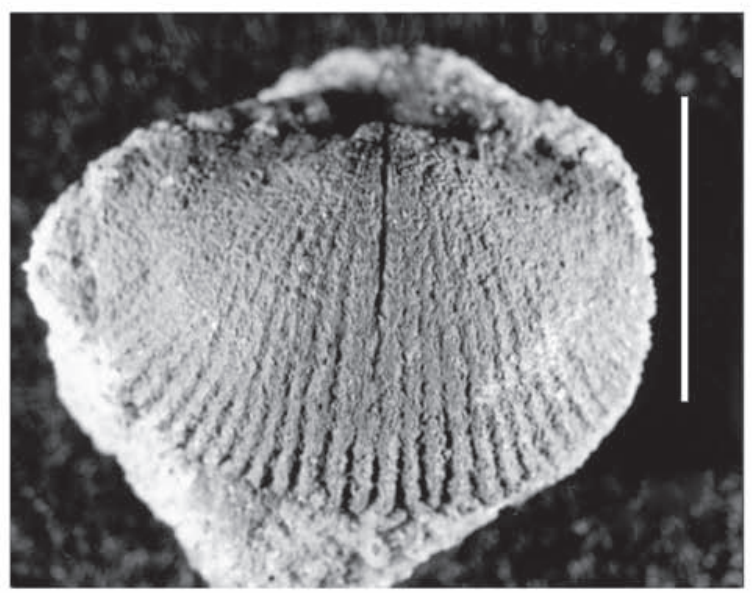

E

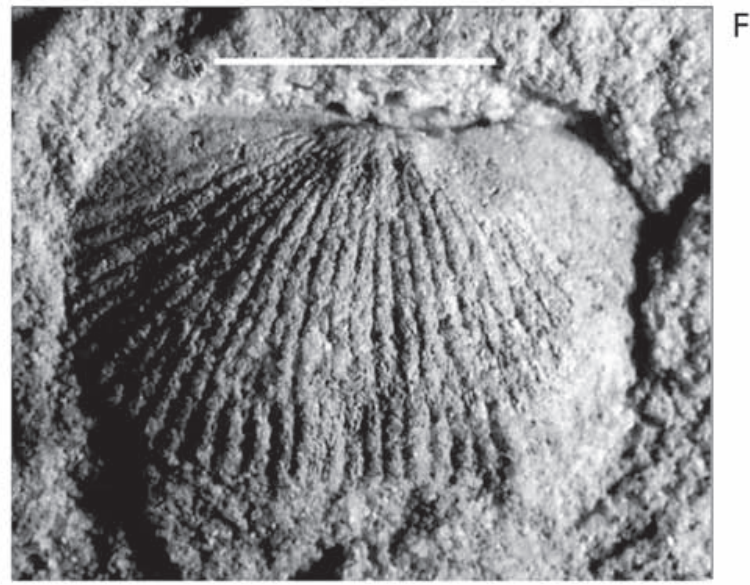

Figura 2. A e B) Montsenetes cf. M. boliviensis Racheboeuf (DGM 6192-lb), região de Picos (MCT 6866-la) e km 3 da BR-407, Picos; C e D) Pleurochonetes comstocki (Rathbun) (MN 7484-la e MN 7478-I), km 305 da BR-316 (Picos-Teresina), arredores de Picos; E e F) "Chonetes" freitasi Rathbun (MN 3433-I), rio Maecuru (MN 7518-I) e margem direita do rio Maecuru, aproximadamente 400 m à montante da cachoeira de Teuapixuna ou Alagação. Figuras A e B: Formação Pimenteira, Piauí; Figuras C e D: Formação Cabeças (Membro Passagem), Piauí; Figuras E e F: Formação Maecuru, Pará. Escala $=10 \mathrm{~mm}$.

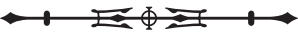



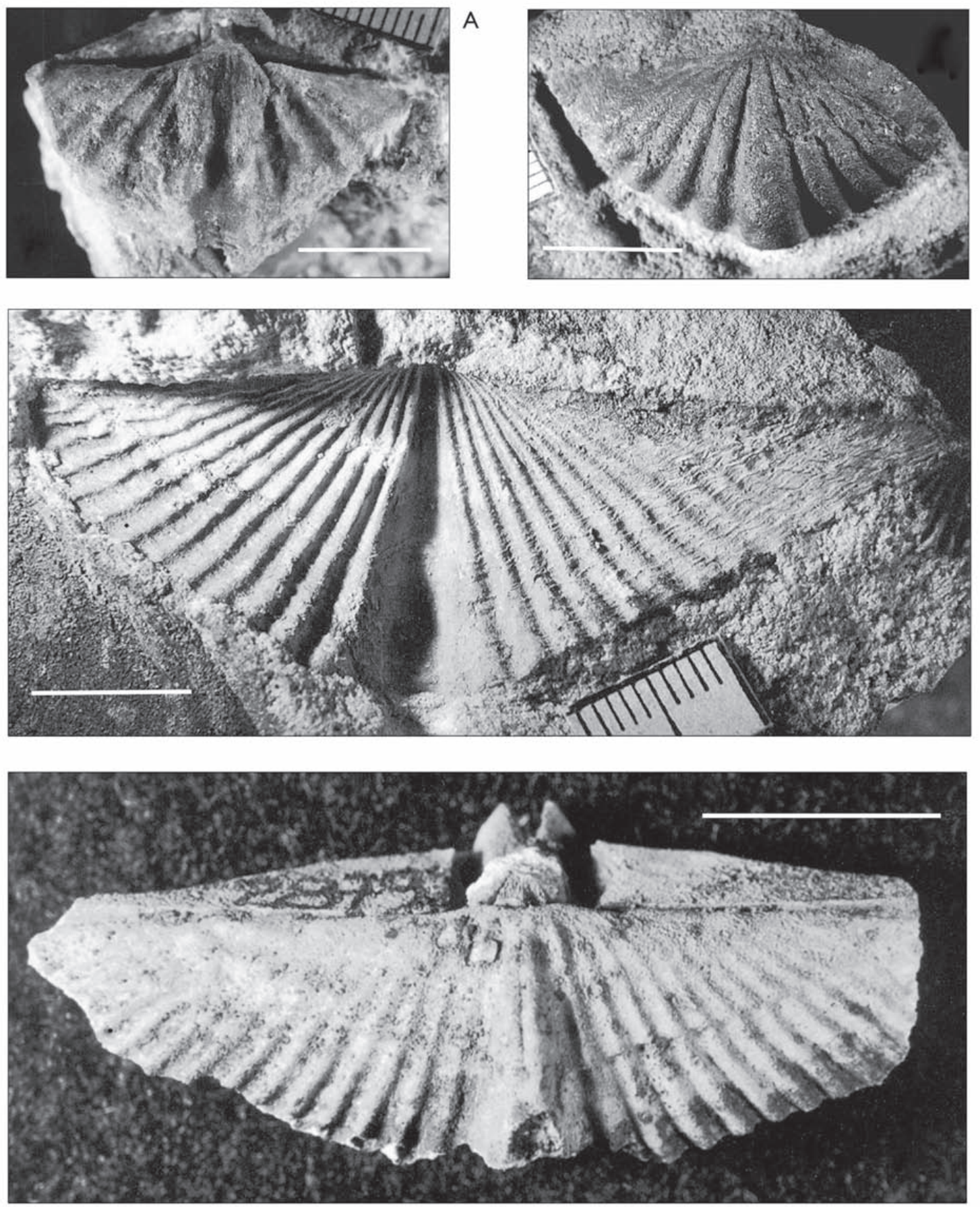

D

Figura 3. A e B) Patriaspirifer? cf. P. duodenarius (Hall) (MN 7527-I), margem direita do rio Maecuru, aproximadamente $400 \mathrm{~m}$ à montante da cachoeira de Teuapixuna (ou Alagação) (MN 3471-I), rio Maecuru; C e D) Mucrospirifer katzeri (Clarke) (DGM 2882-I e DGM 2879-I), rio Maecuru, à montante da cachoeira de Tenapixuna [sic], município de Monte Alegre. Figuras A a D: Formação Maecuru, Pará. Escala $=10 \mathrm{~mm}$ 


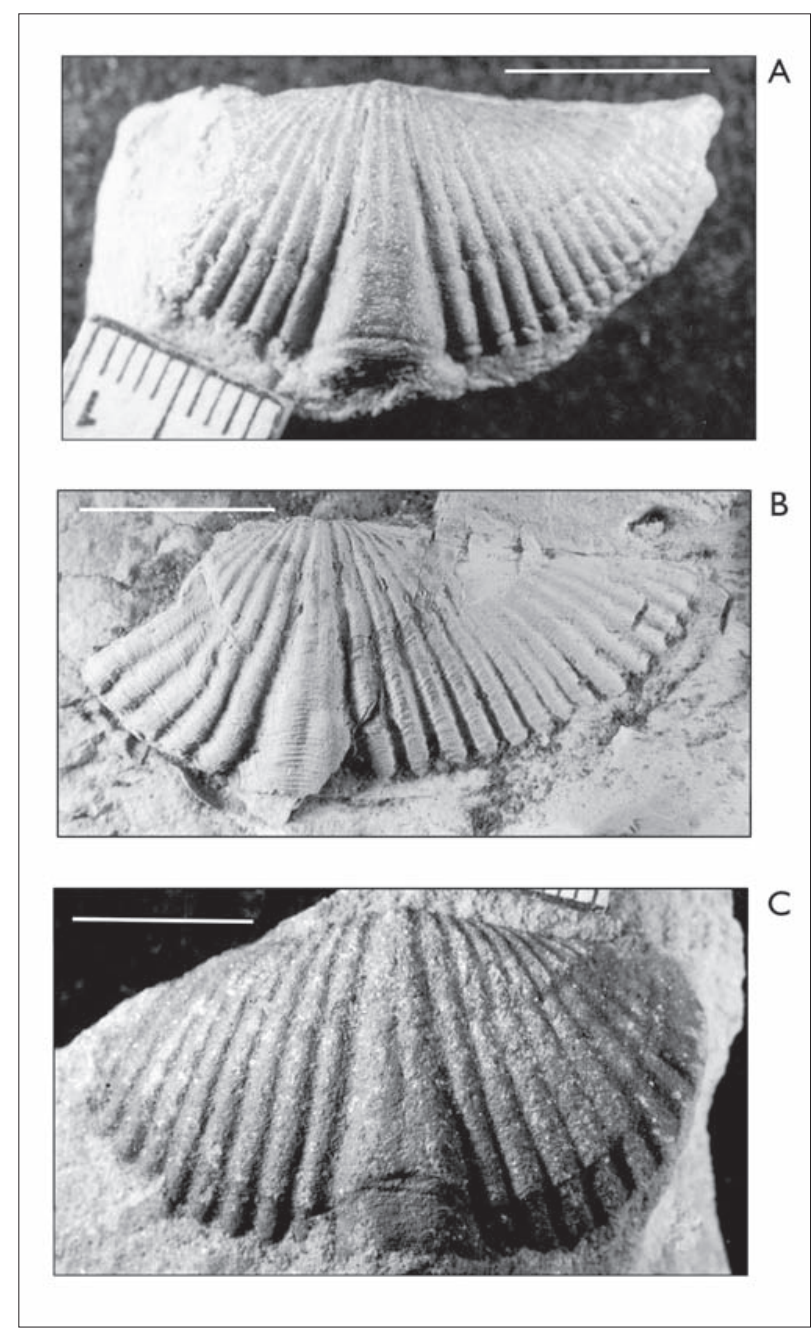

Figura 4. A e B) Mucrospirifer pedroanus (Rathbun) (MN 3463-I), perto de Monte Alegre (DGM 2779-I) e sonda de Itauajuri, município de Monte Alegre; C) Mucrospirifer pedroanus? (Rathbun) (MCT 6870-I), região de Picos. Figuras A e B: Formação Ererê, Pará; Figura C: Formação Cabeças (Membro Passagem), Piauí. Escala $=10 \mathrm{~mm}$.

Alguns gêneros de braquiópodes identificados por Fonseca $(2001,2004)$ reforçaram a constatação da coexistência de formas originárias dos três grandes domínios paleobiogeográficos nas bacias do Amazonas e Parnaíba. Foi verificada também a existência de diacronismo entre as ocorrências desses gêneros nas bacias brasileiras, geralmente mais novos do que os registrados em outras regiões paleogeográficas devonianas. Este fato deve-se provavelmente à existência de barreiras físicas ou ambientais, que se modificaram durante o Devoniano.

Em 2008, braquiópodes coletados na borda sudoeste da Bacia do Parnaíba foram descritos taxonomicamente pela primeira vez, em uma dissertação de mestrado (Gama Jr., 2008). De acordo com o autor, os exemplares foram coletados na base da Formação Pimenteira em dois afloramentos, atribuídos ao Eifeliano Tardio, no município de Palmas (afloramentos Fazenda Encantada e Estância Cantilena), no estado do Tocantins. Foram identificadas no material espécies ocorrentes no Devoniano da Bacia do Amazonas, Montsenetes carolinae, Mucrospirifer pedroanus e um fragmento possivelmente referível a Amphigenia elongata (Vanuxem, 1842), espécie presente nos domínios das Américas Orientais e do Velho Mundo, a espécie cosmopolita Tropidoleptus carinatus (Conrad), além de um Delthyridoidea já assinalado no Devoniano da Bacia do Paraná, no estado de Goiás, e a espécie tipicamente malvinocáfrica Australocoelia palmata (Morris \& Sharpe, 1846), muito abundante no Devoniano Inferior da Bacia do Paraná.

É interessante assinalar as diferenças ambientais que prevaleceram durante o Mesodevoniano entre os sítios deposicionais das atuais bacias do Amazonas e Parnaíba e a maior parte das áreas que constituíam os domínios do Velho Mundo e das Américas Orientais. Enquanto as primeiras localizavam-se em altas latitudes, sujeitas a um regime siliclástico preponderantemente de águas rasas, as regiões ocupadas pelos domínios do Velho Mundo e das Américas Orientais encontravam-se em latitudes equatoriais a tropicais, nas quais predominavam a deposição carbonática ou siliciclástica de águas mais profundas. Embora diversas formas tenham conseguido vencer essa barreira, em geral as associações de braquiópodes diferem em cada uma delas.

Entre as causas prováveis da composição mista das paleofaunas de invertebrados marinhos das citadas bacias, figuram suas posições geográficas, intermediárias entre os três domínios paleobiogeográficos devonianos, e sobretudo a idade eifeliana-givetiana das macrofaunas. Esta idade coincide com as idades estimadas por Boucot (1988)

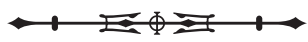


para o desaparecimento do domínio Malvinocáfrico (limite Eifeliano-Givetiano) e do domínio das Américas Orientais (Givetiano). Constata-se que, de uma maneira geral, no Mesodevoniano existiu uma troca de formas entre os três domínios, já não tão bem definidos como no Eodevoniano.

De acordo com o inventário das formas de Chonetoidea do Devoniano da Bolívia, o domínio Malvinocáfrico perdeu seu caráter estritamente endêmico perto do limite Emsiano-Eifeliano no Altiplano e na zona Subandina. Esta perda de individualidade coincide com um período de aprofundamento máximo dos mares malvinocáfricos e com a chegada de Chonetoidea do domínio das Américas Orientais e do Velho Mundo, juntamente com organismos pelágicos, como Goniatites e restos de peixes nos depósitos da Formação Bélen, no Altiplano Boliviano. Acima deste limite, encontram-se as ocorrências das grandes formas de Pleurochonetes e de Montsenetes bolivianus, que atingiram as bacias do Amazonas e do Parnaíba.

Segundo Robardetet al. (1993), existe uma tendência à uniformização das paleofaunas bentônicas do norte do Gondwana e da Laurússia ao longo do Givetiano e Frasniano, devido à deriva do Gondwana para latitudes mais altas e à redução progressiva da barreira oceânica constituída pelo oceano Réico.

Os Chonetoidea do norte da África corroboraram a existência da mistura de faunas também no norte do Gondwana oriental durante o Devoniano. Segundo Racheboeuf(1990), as ocorrências de Chonetoidea devonianas no noroeste da África permitem distinguir duas regiões: uma norte-saariana e uma sul-saariana, separadas pela dorsal Reguibat-Hoggar, de direção W-E. Ao norte da dorsal, a sedimentação marinha do Eodevoniano-Mesodevoniano é contínua e as paleofaunas do Eodevoniano apresentam elementos do domínio do Velho Mundo. No Mesodevoniano, às formas do Velho Mundo vieram se juntar elementos das Américas Orientais que, daí, atingiram o domínio Íbero-Armoricano. Ao sul da dorsal, o Eodevoniano marinho é quase ausente e as faunas mesodevonianas são típicas do domínio das Américas Orientais (sub-província Appohimchi ou Amazono-Colombiana) ou espécies novas originadas deste domínio. Nesta região, a raridade das formas eodevonianas, associada ao caráter transgressivo da base dos depósitos devonianos, sugere que esta região só foi totalmente coberta pelo mar no Mesodevoniano. Durante a transgressão eifeliana, as faunas renano-boêmias não ultrapassaram o eixo Reguibat-Hogar. Os novos domínios marinhos sul-saarianos foram então colonizados por formas oriundas do domínio das Américas Orientais. A colonização foi iniciada por formas pioneiras como Devonochonetes (D. coronatus e Devonochonetes notius (= Montsenetes notius)), e somente após o aprofundamento do ambiente foi possível o estabelecimento de taxa mais estenotípicos como Longispina, que de lá migraram para Europa via região norte-saariana. Por outro lado, a sudoeste da região sul-saariana (Senegal, Guiné-Bissau), elementos do domínio das Américas Orientais mesclam-se a formas malvinocáfricas. De acordo com Boucot (1988) e Melo (1988), é descrita também na literatura a ocorrência de misturas de faunas malvinocáfricas e das Américas Orientais, em Gana.

A interpretação apresentada anteriormente para a distribuição paleogeográfica dos Chonetoidea da região sul-saariana pode ser aplicada, em alguns aspectos, às bacias do Amazonas e do Parnaíba. Os arenitos transgressivos das formações Maecuru e Pimenteira são portadores de espécies do gênero Montsenetes. Montsenetes carolinae, da Formação Maecuru, é muito semelhante à $M$. notius, do Eifeliano tardio-Givetiano inicial da Serra de Perijá, na Venezuela. Montsenetes cf. M. bolivianus, da Formação Pimenteira, parece ser a mesma forma encontrada no membro superior da Formação Bélen (provavelmente Givetiano), do Altiplano boliviano. Além disso, as formas aqui referidas à "Chonetes freitasi", muito abundantes na Formação Maecuru, apresentam morfologia externa semelhante a Devonochotes (Eifeliano-Givetiano de New York, Grupo Hamilton, EUA), embora de maior tamanho. Na Formação Ererê, aparecem Chonetoidea, "Chonetes" herbertsmith e "Chonetes" onettianus, cujo morfotipo (tamanho pequeno e a convexidade acentuada da valva ventral) é semelhante 
ao de Longispina (Eifeliano-Givetiano dos EUA, Venezuela, Bolívia, Marrocos, Argélia, Espanha e França).

Entretanto, juntamente com as formas citadas no parágrafo anterior, foram identificados, nos arenitos da Formação Ererê e do Membro Passagem, grandes exemplares de Chonetoidea referidos à Pleurochonetes comstocki. Segundo Racheboeuf (1998), o gênero Pleurochonetes ocorre no domínio Malvinocáfrico do Emsiano (África do Sul, Bolívia e Argentina) ao Eifeliano (Bolívia). No entanto, no mesmo trabalho, incluiu a espécie originalmente descrita como Gamonetes altaicus, do Devoniano da Mongólia, na lista de espécies referidas a este gênero, e considerou Chonetes seillouensis, da porção inferior do maciço Armoricano (Devoniano Inferior), na França, uma espécie de Pleurochonetes. A espécie da Mongólia não foi possível avaliar. Quanto à espécie da França (descrita originalmente como Notiochonetes? seillouensis), o exame da estampa 34, figuras 18-21, de Racheboeuf (1981), parece corroborar sua designação ao gênero Pleurochonetes. A presença do gênero Pleurochonetes nesta região da Europa e nas bacias do Amazonas, do Parnaíba e do Paraná (segundo Fonseca, 1998, Pleurochonetes falklandicus ocorre na Formação Ponta Grossa em afloramentos provavelmente de idade pragiana e emsiana) amplia sua distribuição estratigráfica. Sua ocorrência no Eodevoniano do maciço Armoricano (a ocorrência mais antiga do gênero) já tinha chamado a atenção de Boucot (1988), que, embora tenha salientado a dificuldade de interpretá-la, sugeriu a possibilidade de ter havido algum tipo de comunicação entre a região do maciço Armoricano e a Província Malvinocáfrica.

Entre os Delthyridoidea identificados, de acordo com Bizzarro \& Lespérance (1999), as ocorrências de Patriaspirifer no Eodevoniano-Mesodevoniano da América do Norte (EUA e Canadá, na península de Gaspé) e da América do Sul (Venezuela) estão restritas ao domínio das Américas Orientais. Mucrospirifer é considerado por Pitrat (1965) um gênero cosmopolita.

Segundo Harper Jr. \& Boucot (1978), os gêneros de "estrofodontoides" do Eodevoniano-Mesodevoniano dos domínios das Américas Orientais e do Velho Mundo eram numerosos e altamente endêmicos. Por outro lado, um único gênero, Protoleptostrophia, é conhecido do domínio Malvinocáfrico. É interessante assinalar a quase ausência desse grupo nas bacias brasileiras. As espécies até hoje identificadas estão restritas à Formação Maecuru, e pertencem a dois gêneros e um subgênero. São eles: Protoleptostrophia, gênero difundido no domínio das Américas Orientais, mas também presente nos outros dois domínios; Megastrophia (Megastrophia), restrito ao Eodevoniano-Mesodevoniano da sub-província Appohimchi, além de um gênero novo. A ausência de "estrofodontoides" nas formações Ererê e Cabeças, aliada à presença do gênero Pleurochonetes, amplia a provável influência das faunas "malvinocáfricas" do sul do Gondwana (principalmente da Bolívia) nas bacias do Norte e Nordeste do Brasil.

\section{CONCLUSÕES}

Foi corroborada a composição mista das paleofaunas de braquiópodes devonianas das bacias do Amazonas e do Parnaíba. As relações das duas bacias brasileiras com bacias do Gondwana norte-ocidental (noroeste da África e Armórica ou Europa norte-gondwânica) necessitam ser aprofundadas em estudos futuros. Em relação à Armórica, alguns táxons, não só de braquiópodes mas também de outros grupos de paleoinvertebrados brasileiros, como os crinoides, sugerem uma troca faunística entre as duas regiões durante esse período de tempo.

\section{REFERÊNCIAS}

BIZARRO, M. \& P. J. LESPÉRANCE, 1999. Systematics of some Lower and Middle Devonian spiriferid brachiopods from Gaspé with a revision of the superfamily Delthyridoidea. Journal of Paleontology 73(6): 1056-1077.

BOUCOT, A. J., 1988. Devonian biogeography: an update. In: N. J. MCMILLAN, A. F. EMBRY \& O. J. GLASS (Eds.): Devonian of the world: v. 1: 211-227. Canadian Society of Petroleum Geologists, Calgary.

CARVALHO, R. G., 1975. Braquiópodes devonianos da bacia do Amazonas: Orthida, Strophomenida, Spiriferida e Terebratulida.

Boletim do Museu Paraense Emílio Goeldi, Nova Série, Geologia 21: 1-35.

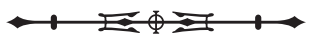


CUNHA, P. R. C., J. H. G. MELO \& O. B. SILVA, 2007. Bacia do Amazonas. Boletim de Geociências da Petrobras 15(2): 227-251.

FONSECA, V. M. M., 1998. A ocorrência de Pleurochonetes falklandicus (Morris \& Sharpe) (Brachiopoda) no Devoniano da Bacia do Paraná. Anais da Academia Brasileira de Ciências 70(2): 377-378

FONSECA, V. M. M., 2001. Brachiopoda (Strophomenoidea, Chonetoidea e Deltyridoidea) do Devoniano Médio das bacias do Amazonas e Parnaíba: 1-197. Tese (Doutorado em Geologia) Universidade Federal do Rio de Janeiro, Rio de Janeiro.

FONSECA, V. M. M., 2004. Chonetoidea (Brachiopoda) do Devoniano Médio das bacias do Amazonas e Parnaíba, Brasil. Arquivos do Museu Nacional 62(2): 193-215.

FONSECA, V. M. M. \& J. H. G. MELO, 1987. Ocorrência de Tropidoleptus carinatus (Conrad) (Brachiopoda, Orthida) na Formação Pimenteira, e sua importância paleobiogeográfica. Anais do Congresso Brasileiro de Paleontologia 10(2): 505-537.

FONSECA, V. M. M. \& L. C. M. O. PONCIANO, 2011. Braquiópodes do Devoniano Médio das Bacias do Amazonas e Parnaíba. In: I. S. CARVALHO, N. K. SRIVASTAVA, O. STROHSHOEN JR. \& C. C. LANA (Eds.): Paleontologia: cenários de vida: v. 4: 170-190. Interciência, Rio de Janeiro.

GAMA JR., J. M., 2008. Braquiópodes da Formação Pimenteiras (Devoniano Médio/Superior), na região sudoeste da Bacia do Parnaíba, Município de Palmas, Estado do Tocantins, Brasil: 1-74. Dissertação (Mestrado em Geologia) - Universidade de Brasilia, Brasília.

GRAHN, Y. \& J. H. G. MELO, 2004. Integrated Middle Devonian chitinozoan and miospores zonation of the Amazonas Basin, northern Brazil. Revue de micropaléontologie 47: 71-85.

GRAHN, Y., C. YOUNG \& L. BORGHI, 2008. Middle Devonian chitinozoan biostratigraphy and sedimentology in the eastern outcrop belt of the Parnaíba Basin, Northeastern Brazil. Revista Brasileira de Paleontologia 11(3): 137-146.

HARPER JR., C. W. \& A. J. BOUCOT, 1978. The Stropheodontacea. Part III: Stropheodontidae (sensu strictu), Pholidostrophiidae and Lissostrophiidae. Palaeontographica 162(1-2): 1-80.

KEGEL, W., 1953. Contribuição para o estudo do Devoniano da bacia do Parnaíba, Brasil. Boletim da Divisão de Geologia e Mineralogia 141: 1-48.

MELO, J. H. G.,1985. A província Malvinocáfrica no Devoniano do Brasil: estado atual dos conhecimentos. Dissertação (Mestrado em Geologia) - Universidade Federal do Rio de Janeiro, Rio de Janeiro.
MELO, J. H. G., 1988. The Malvinokaffric realm in the Devonian of Brazil. In: N. J. MCMILLAN, A. F. EMBRY \& O. J. GLASS (Eds.): Devonian of the world: v. 1: 669-703. Canadian Society of Petroleum Geologists, Calgary.

MELO, J. H. G. \& S. LOBOZIAK, 2003. Devonian-Early Carboniferous miospore biostratigraphy of the Amazon Basin, Northern Brazil. Review of Palaeobotany and Palynology 124(3-4): 131-202.

PITRAT, C. W., 1965. Suborder Spiriferidina. In: R. C. MOORE (Ed.): Treatise on invertebrate Paleontology, Part $\mathrm{H}$, Brachiopoda: 2: H667-H728. Geological Society of America e University of Kansas Press, Lawrence.

PONCIANO, L. C. M. O., V. M. M. FONSECA, A. C. S. FERNANDES, D. M. C. MACHADO \& A. R. SOUZA, 2013. Afloramento fossilífero de Oiti, Bacia do Parnaíba, PI - registro de um mar devoniano no Nordeste do Brasil. In: M. WINGE, C. SCHOBBENHAUS, C. R. G. SOUZA, A. C. S. FERNANDES, M. BERBET-BORN, W. SALUM FILHO \& E. T. QUEIROZ(Eds.): Sítios geológicos e paleontológicos do Brasil: 3: 191-200. CPRM, Brasília.

RACHEBOEUF, P. R., 1981. Chonétacés (brachiopodes) siluriens et dévoniens du sud-oest de l'Europe. Mémoires de la Société Geologique et Mineralogique de Bretagne 27(294): 1-294.

RACHEBOEUF, P. R., 1990. Paléobiogéographie de la marge nordgondwanienne au Dévonien inférieur et moyen: nouvelles données déduites de l'étude des Brachiopodes Chonetacés. Comptes Rendues de Académie de Sciences de Paris 310(II): 1481-1486.

RACHEBOEUF, P. R., 1998. The chonetoidean brachiopods: a revised and updated systematic and bibliographic catalogue. Documents des Laboratoires de Geologie de Lyon 148: 1-178.

RATHBUN, R., 1874. On the devonian Brachiopoda of Ererê, province of Pará, Brazil. Bulletin of the Bufallo Society of Natural Sciences 1: 236-261.

RATHBUN, R., 1879. The devonian Brachiopoda of the province of Pará, Brazil. Proceedings of the Boston Society of Natural History 20: 14-39.

ROBARDET, M., J. BLAISE, E. BOUYX, R. GOURVENNEC, H. LARDEAUX, A. LE HERRISSE, J. LE MENN, M. MELOU, F. PARIS, Y. PLUSQUELLEC, J. PONCET, S. REGNAULT, M. RIOULT \& M. WEYANT, 1993. Paléogéographie de l'Europe occidentale de l'Ordovicien au Devonian. Bulletin de la Societé Geologique de France 164(3): 683-695.

VAZ, P. T., N. G. A. M. REZENDE, J. R. WANDERLEY FILHO \& W. A. S. TRAVASSOS, 2007. Bacia do Parnaíba. Boletim de Geociências da Petrobras 15(2): 253-263.

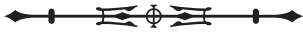


